\title{
The Effect of Deformation in the Two-Phase Region of C-Mn and Microalloyed Steels on the Mechanical Behaviour of the Resulting Structure
}

\author{
J. Majta, A. Zurek* and M. Pietrzyk \\ University of Mining and Metallurgy, Faculty of Metallurgy and Materials Science, 30-059 Krakow, \\ Poland \\ *Los Alamos National Laboratory, Los Alamos, NM 87545, U.S.A.
}

\begin{abstract}
The paper presents results of experimental research and a model implementation of hot deformation process in the two-phase region for microalloyed and plain carbon steels. Hot compression tests were employed to determin the behavior of deformed steel over a range of strain rates $\left(1 \times 10^{-3}-2.5 \times 10^{3} \mathrm{~s}^{-1}\right)$ and temperatures $(650$ $1050{ }^{\circ} \mathrm{C}$ ). The hot deformation conditions during the test were simulated using Finite Element Method. The thermomechanical history of the material is consequently integrated in the simulation. The investigation was focused on the case when the last deformation takes place in the two phase or ferrite region. Such deformed material was investigated to obtain the microstructure development and its influence for mechanical properties in final product.

Résumé: Nous présentons des résultats expérimentaux et ceux d'une modélisation d'un procédé de déformation á chaud pour des aciers au carbone ou microalliés, dans le domaine biphasé. Nous déterminous le comportement en compression á chaud $\left(1 \times 10^{-3} \div 2,5 \times 10^{3} \mathrm{~s}^{-1}, 650<\mathrm{T}<1050^{\circ} \mathrm{C}\right)$ de l'acier pré-déformé. Les conditions de déformation á chaud ont également été simulées par une méthode á éléments finis afin d'intégrer l'histoire thermomécanique. Nous examinons particuliérement, ici, le cas oú la derniére déformation se produit dans une région biphasée ou ferritique. Nous étudions un matériau ainsi déformé pour déterminer l'évolution de la microstructure et son influence sur les propriétés mécaniques du produit final.
\end{abstract}

\section{INTRODUCTION}

The final mechanical properties of hot deformed plain carbon or microalloyed steels are related to the room temperature microstructure first of all through the appropriate ferrite structure-property relationship. It is well known that the ferrite grain size is a function of the composition, austenite grain size, cooling rate and level of retained strain in the austenite at transformation. In an overwhelming majority the industrial manufacturing of steel products starts with a hot forming process (thermomechanical controlled process) where the finishing stage is performed in the austenitic phase. However, it can be stated that a significant improvement of the strength of both HSLA and plain carbon steel can be expected from modern thermomechanical procedures carried out in the two-phase region or in the ferrite region. In the case when modern thermomechanical process is employed and the effects of low finish deformation temperature started be significant, others features of such a process should be taken into account. For example, during hot deformation processes a significant temperature drop can develop near the contact surfaces between the material and the tool. Additionally, when the finishing of the deformation process occurs at low temperatures, but just above the transformation start temperature, a large volume of the material is in the two-phase regime and have different flow description. The problem of inhomogeneity of microstructural development in hot formed products is still not well understood. This situation may strongly affect materials damage behavior. Monitoring the impact of the hot deformation conditions on the microstructure development, precipitation process, and resulting defects (i. e., subgrains, dislocation structure, and deformation bands) under industrial conditions is difficult and expensive. The control of the strength and quality of steel is strongly dependent on correctness of relationships between microstructural parameters and mechanical properties. Thus, the purpose of the present work is an investigation of the effects of hot deformation process occurring in the two phase region of plain carbon and microalloyed steels and their impact on the mechanical properties of the resulting product. The work is a part of larger 
project focused on deformation in the two-phase region. The uniaxial compression tests, conducted in a range of strain rates from $10^{-3} \mathrm{~s}^{-1}$ to $50 \mathrm{~s}^{-1}$, were provided using an tension-compression testing machine and additionally split Hopkinson pressure bar for strain rate $2.5 \times 10^{3} \mathrm{~s}^{-1}$. Each of the experiments was performed in a range of temperature corresponding to the austenite, two phase, and ferrite regions Samples were deformed in isothermal or continuos cooling conditions at required temperatures to obtain varied resulting microstructure and recovery effects. The objectives of theoretical work were threefold: 1) to improve the existing microstructural evolution models for the deformation in the austenite region, 2) to develop the transformation model and microstructure evolution models for the two-phase and ferrite regions, and 3) to improve the existing model for mechanical properties of final products.

\section{MODELING THE MECHANICAL RESPONSE OF THE HOT DEFORMED MATERIAL}

The mechanisms affecting the mechanical properties of the hot deformed steel usually have been studied from several aspects. In the literature, data for the prediction of mechanical properties in final product have normally been presented as a function of the solid solution and grain size strengthening components. However, the mechanical response of a material is a consequence of its more complex internal microstructure. The previously published papers $[1,2]$ described the major features of the model for each of the microstructural events that occur during the hot metal forming process and present the influence of a particular strengthening mechanisms that determine the mechanical properties.

The modeling for the evolution of microstructure is based on the modified Avrami equation. The microstructural model employed in this work is described in detail in published reports $[2,3]$. The model connects an advanced finite-element approach, simulating metal flow and heat transfer during hot plastic deformation [4], with the conventional equations describing microstructural processes. The temperature field, computed by the thermal portion, is used in the model to calculate all temperature-dependent properties and parameters upon which the first set of dependent variables is determined. Using the resulting strain and temperature fields, the microstructure development was modeled and the fractional softening was calculated. The kinetic of the phase transformation (austenite - ferrite, pearlite) was then evaluated. The resulting model was used to calculate the amount of the strain accumulated in particular phases, and finally the mechanical properties were calculated.

In steel, particularly in microalloyed steels, the yield strength is a complex combination of the relevant strengthening contributions that are connected with the thermomechanical history of the deformed material. For correct illustration for the structure-property relation, the following factors have been taken into consideration:

- matrix strengthening: inherent friction stress, solid solution strengthening (by substitutional

alloying elements and by interstitial atoms), $\sigma_{o}, \sigma_{s s}$

- dispersion strengthening (precipitation hardening), $\sigma_{p}$

- dislocation strengthening (due to forest dislocation), $\sigma_{d}$

- grain boundary strengthening: high angle grain and sub-structure or sub-grain size strengthening, $\sigma_{g}, \sigma_{s g}$

- texture strengthening, $\sigma_{t}$

In the present work, the strengthening components due to the interactions between forest dislocations and mobile dislocations are separated, and all other contributions that are friction stress, Orowan stress etc., are collected as a second major strengthening component. It has been pointed out elsewhere $[5,6]$. that when experimental results are fitted by a root of the sum of the squares summation (r.s.s), the agreement between the measured and calculated yield strength is much closer than when a linear summation is used. Using the r.s.s summation, the yield strength is expressed as a sum of two parts: matrix strengthening $\left(\sigma_{o}, \sigma_{s s}, \sigma_{p}\right)$ together with grain boundary strengthening $\left(\sigma_{s g}, K_{y} d^{1 / 2}\right)$ and dislocation strengthening $\left(\sigma_{d}\right)$ :

$$
\begin{aligned}
& Y S=\left[\left(\sigma_{o}+\sigma_{s s}+\sigma_{p}+\sigma_{s g}+\sigma_{t}+\sigma_{g}\right)^{2}+\sigma_{d}^{2}\right]^{1 / 2} \\
& \text { where } \sigma_{g}=K_{y} d^{-1 / 2}
\end{aligned}
$$


When the yield strength of the second phase (pearlite, bainite) is known, the total strengthening is obtained by the mixture rule.

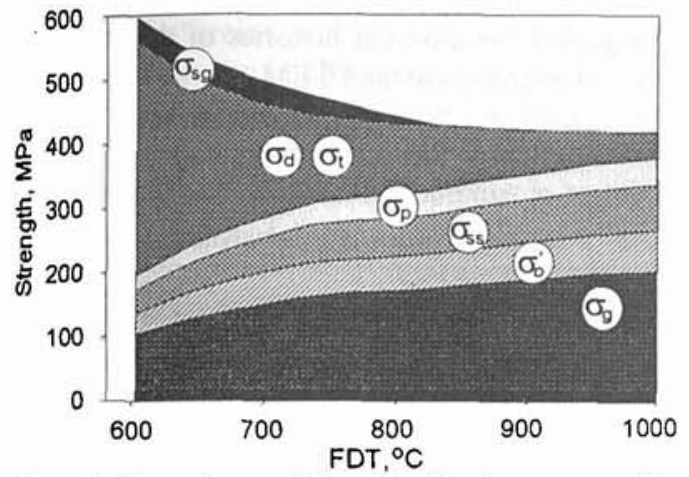

Figure 1: Dependence of the strengthening components on the finish deformation temperature. Results of calculation by Eq. (1) $[2,6]$

The above mentioned relationships, together with the microstructural model employed in the finite element model of the process, enable the prediction of the contribution of various components to the mechanical properties in the final product as a result of different thermomechanical histories (see Fig. 1).

\section{EXPERIMENTS}

The objective of the experiments was to obtain data concerning the effects of the thermomechanical history. The compression tests were performed under various strain rate conditions with different finish deformation temperatures (Fig. 2). The development of the microstructure as affected by the strain rate, strain and temperature was observed on the ferrite grain sizes and, in consequence, on the yield strength distribution in the final product. The test materials were a plain carbon steel with high manganese content what gives a relatively low transformation start

Table 1: Chemical composition (in wt\%) of the steels investigated.

\begin{tabular}{lccccccc}
\hline Designation & $\mathrm{C}$ & $\mathrm{Mn}$ & $\mathrm{Si}$ & $\mathrm{Al}$ & $\mathrm{Nb}$ & $\mathrm{Ti}$ & $\mathrm{N}$ \\
C-Mn & 0.21 & 1.37 & 0.28 & - & - & - & 0.0065 \\
HSLA & 0.067 & 1.30 & 0.34 & 0.037 & 0.076 & 0.024 & 0.0054 \\
\hline
\end{tabular}

temperature, and high niobium steel. The chemical compositions of these steels are shown in Table 1. During the tests for C-Mn steel, first deformation was applied at temperature of $1050{ }^{\circ} \mathrm{C}$. Further, the

specimens were allowed to cool in air to the temperature of second stage. The hot deformation which, involves dynamic transformation of austenite to ferrite, was followed using continuous cooling compression. Tests were done at temperatures (measured in the centre of the specimen) of 850,720 and $650^{\circ} \mathrm{C}$. Homogeneous strains of $0.2,0.5$ and 0.8 were employed in the second stage for each of the deformation temperatures. The heating and deformation conditions are shown schematically in Figure 2a.

After compression, the samples were sectioned and minispecimens were cut out from the central part. These were subjected to tensile test. The yield strength, tensile strength, reduction of area, total elongation, and hardness were measured.

a)

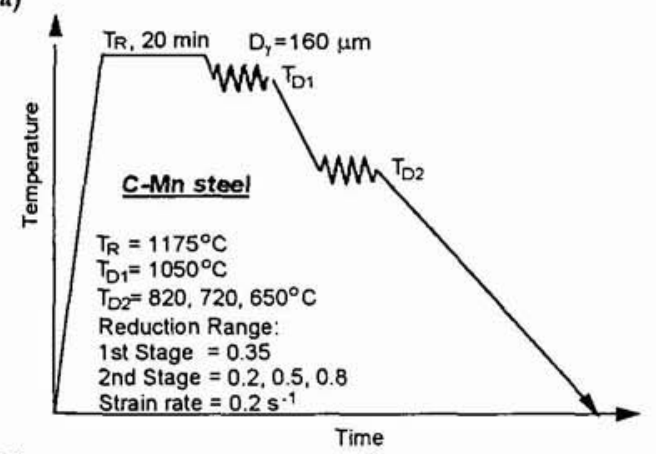

b)

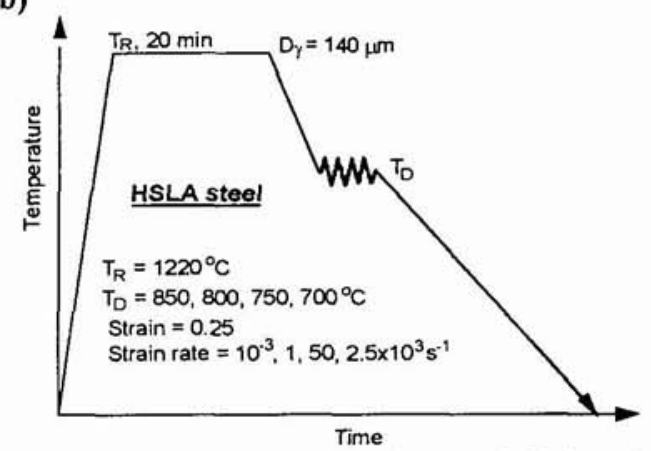

Figure 2: Schematic representation of the thermomechanical treatments; a) two-stage compression test of C-Mn steel, continuous cooling procedure; $\mathrm{T}_{\mathrm{D} 1}$ - first stage temperature, $\mathrm{T}_{\mathrm{D} 2}$ - second stage temperature. b) one-stage compression test of HSLA steel, isothermal conditions; $T_{R}$ - reheating temperature.

The uniaxial compression tests of HSLA steel were performed in a range of strain rates from $10^{-3} \mathrm{~s}^{-1}$ to $2.5 \times 10^{3} \mathrm{~s}^{-1}$ using an MTS testing machine and split Hopkinson pressure bar. Each experiment was 
performed in a range of temperatures corresponding to the austenite, two-phase, and ferrite regions Samples deformed at required temperatures were cooled with different cooling rate. The thermomechanical history for these experiments is shown in Fig. 2b. The treatments are different for each of the steels to make possible the analysis of the resulting structure and properties for different histories of deformation The deformed samples of both steels were analyzed using optical microscopy and TEM.

\section{RESULTS AND ANALYSIS}

The behavior of hot deformed steels is controlled by several features of the material structure that also determine the ferrite structure, as well as the final mechanical properties of the product. Generally, it can be stated that the austenite grain size, cooling rate, and total accumulated strain, determined by the finish deformation temperature (FDT), interpass time, and prestrain, control the ferrite grain size in the final product. In the partially recrystallized and the unrecrystallized state, the softening of austenite by the restoration process proceeds only partially, and the residual work hardening accumulates from the succeeding deformation passes. This effect is especially important in the case of HSLA steel. Therefore, in the estimation of the ferrite grain size, transformed from such austenite structure, all of the above mentioned elements must be taken into consideration. Both deformation before and after the transformation start temperature cause grain refinement, but at different levels and by different mechanisms. It has been shown that there is a significant change

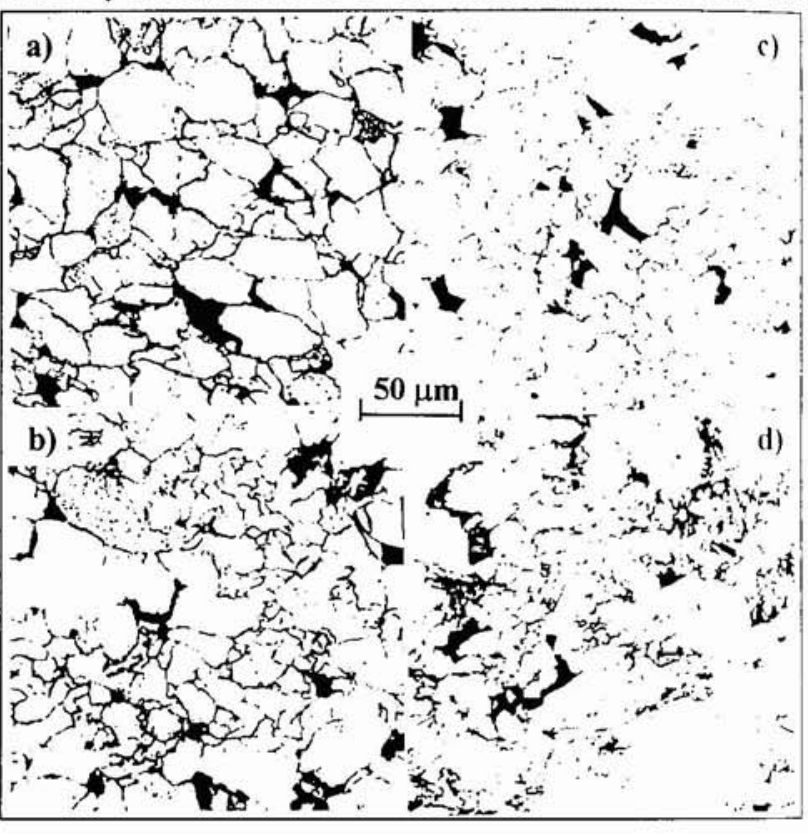

Figure 3. Optical micrographs of HSLA steel deformed with different strain rates and at different temperatures. a) b) $850,700{ }^{\circ} \mathrm{C}$. strain rate $=50 \mathrm{~s}^{-1}$; c) d) $850,700^{\circ} \mathrm{C}$, strain rate $=0.001 \mathrm{~s}^{-1}$. after 1.1 total strain compared to the case of 0.4 strain [1]. This is presumably because the grains are not nucleated at the same time and under the same conditions. Thus, each grain has a different growth time and appears in a region with a different nucleus density. Photomicrographs obtained and included here, show the heterogeneous mixture of ferrite grain size, with significant refinement at the heavy deformed austenite grains (see Fig. 3). It can be seen also that the strain rate has a significant influence on the final ferrite

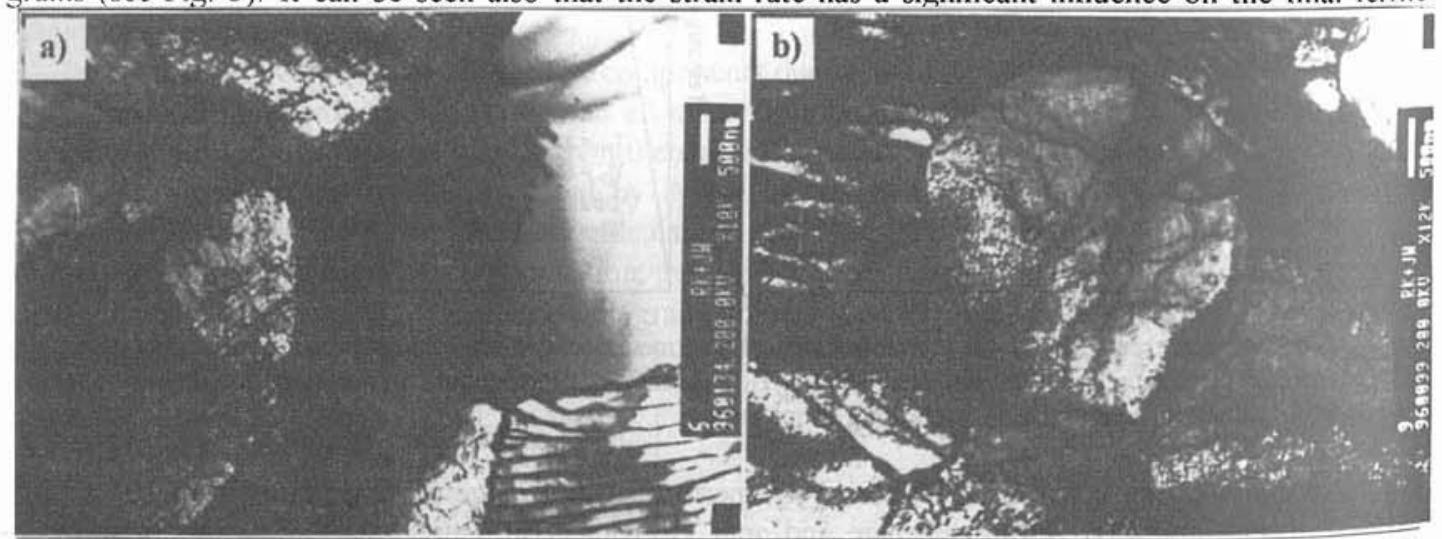

Figure 4. Transmission electron micrographs of C-Mn steel deformed at a) 720 and b) $650{ }^{\circ} \mathrm{C}$. (2nd stage with strain=0.8) 
structure. In order to more closely investigate the effects of deformation in temperatures around $A r_{3}$, TEM microscopy was performed (see Fig. 4). The preliminary TEM results show that the specimens deformed around the $\mathrm{Ar}_{3}\left(\mathrm{FDT}=720^{\circ} \mathrm{C}\right.$ ) have $20-30 \%$ of grains with significantly increased dislocation density. The grains without dislocations also exist in these specimens. As was expected, the higher dislocation density is observed at lower deformation temperatures. In the case of deformation at $650{ }^{\circ} \mathrm{C}$, around $50 \%$ of the grains have increased dislocation density. These observations suggest necessity of including the number of grains with dislocations in the model. The final product of the hot forming process and its mechanical properties is highly dependent on the inhomogeneity of the defects that accumulate as a result of distribution of the retained strain between ferrite and austenite phases (Fig.5).
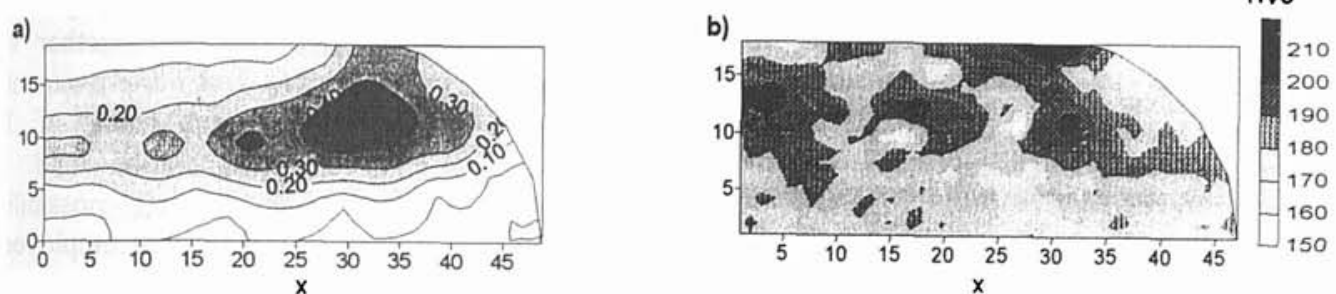

Figure 5: Comparison of computed effective strain in ferrite phase (a) and experimental measured hardness distribution b). Specimen deformed at $720^{\circ} \mathrm{C}$. C-Mn steel.

Results presented in Fig. 5 suggest a clear interaction between the amount of strain concentrated in ferrite phase and hardness distribution in final product. This effect is expected to be more significant with decreasing of FDT. Additionally, it is known and has been proved experimentally that ferrite grains are much softer than austenite grains. Thus in the two phase region, the plastic deformation concentrates in the ferrite phase to a greater extent and the strain in austenite remains smaller than expected.
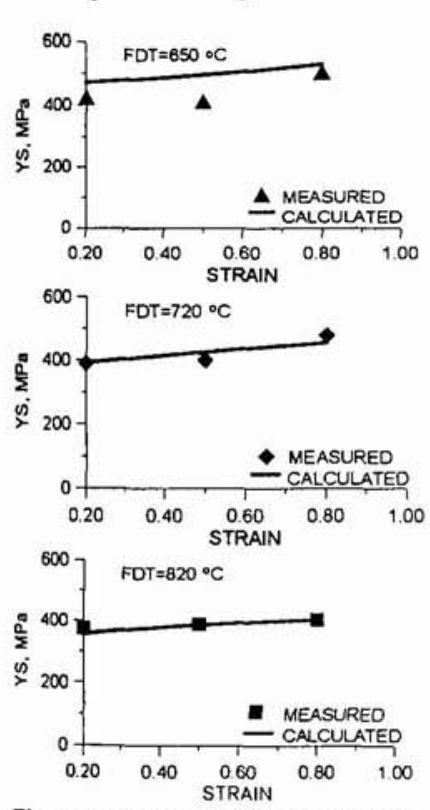

Figure 6.Variation of yield strength with strain for different finish deformation temperature. C-Mn steel.
Strain has a strong effect on ferrite grain refinement at temperatures just below $A r_{3}$. As was shown elsewhere [1] and proved here, at $650{ }^{\circ} \mathrm{C}$ the ferrite occupies most of the available austenite grain boundary area. Thus, deformation of this structure should lead to larger, pancaked, ferrite layers of similar dimension and volume fraction at the austenite grain boundaries, plus finer, strain-induced ferrite at the ferrite-austenite interfaces. The transformation start temperature, as calculated and observed in

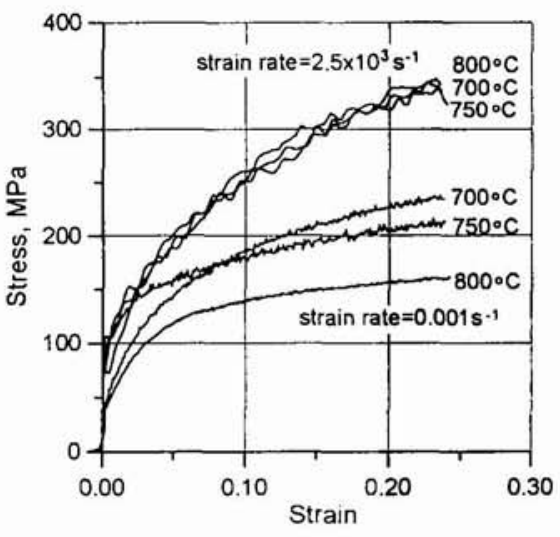

Figure 7. Effect of strain rate and finish deformation temperature on the stress-strain curves. HSLA steel. the experiments, is in the range of $710-735{ }^{\circ} \mathrm{C}$ for $\mathrm{C}-\mathrm{Mn}$ and $740-760^{\circ} \mathrm{C}$ for HSLA steel. Since the strain rate and cooling rate were kept constant by decreasing the deformation start temperature, the amount of retained strain in ferrite was increased. This involves increasing the yield strength at room temperature. On the other hand deformation increases the transformation rate of austenite. Thus, the ferrite content can increase at higher finish deformation temperatures. When the deformation is completed in the austenite region, the dislocation density in the ferrite structure is relatively low. When the deformation is extended to the austenite-ferrite or the ferrite region, the dislocation 
strengthening becomes much more significant and this results in higher yield stress (see Fig. 6.). The dislocation contribution to strengthening is very complex and usually is an effect of the interactions between the forest dislocations, mobile dislocations and substructure. Because of the different driving force after deformation in two phase region, when the recovery process occurs during cooling, the inhomogeneity in final product increases significantly (see Fig.3). However, the refined structure of ferrite obtained from deformed and unrecrystallized austenite seems to have stronger influence on the yield strength than dislocation and substructure strengthening (see Fig. 8). This behavior needs further
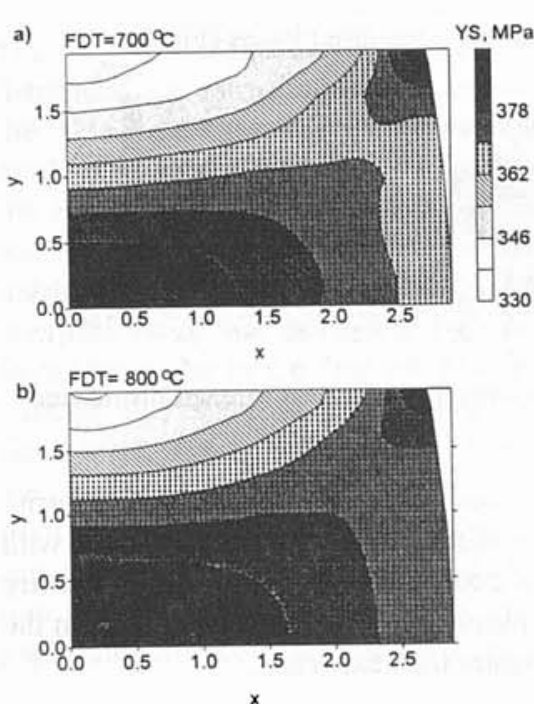

Figure 8. Example of calculations.

Variations in yield strength distributions with temperature of finish deformation in:

a) austenite-ferrite and b) austenite structure. Strain $=0.25$. strain rate $=1 \mathrm{~s}^{-1}$. HSLA steel. investigations, but generally it can be expected that the real improvement in mechanical properties can be obtained in this way: conducted thermomechanical treatment. Especially in Vibtreated HSLA steels, refined ferrite structure, together with additional dislocation strengthening, can lead to improvement of mechanical properties. Because of the influence of $\mathrm{Nb}$. precipitates on austenite static recrystallization and $\gamma / \alpha$ transformation, the HSLA steel demonstrate better possibilities for such treatment. When the high strain rate was employed in the compression tests, the absence of the effects of phase transformation beginning in the stress-strain curves was observed, as can be seen clearly in the case of low strain rate (see Fig. 7). All of these observations show the necessity of further investigations that should be focused on the relationship between the themomechanical history of the deformation process and the mechanical behavior of the resulting structure.

As it was mentioned earlier, this present work is a part of a larger project, and all of above-discussed results will support further research work and will be employed in future experimental work and modeling as well.

\section{CONCLUSIONS}

A methodology for computing microstructural development resulting after hot compression tests of plain carbon and microalloyed steels was presented. A finite element model, containing a macroscopic description of strengthening mechanisms, has been used to make predictions of mechanical properties. It has been experimentally demonstrated that the proposed model can predict with good accuracy the evolution of the microstructure for different thermomechanical histories. The investigations were focused on the description of the influence of deformation in two-phase or ferrite region on the strengthening mechanisms.

\section{Acknowledgments}

The authors appreciate the assistance given by Carl Cady, Bob Carpenter and Mike Lopez (Los Alamos National Laboratory) in compression tests of HSLA steel.

\section{References}

[1] Majta J., Kuziak R., Pietrzyk M. and Krzton H., Journal of Materials Processing Technology, 60 (1996) 582-588

[2] Majta J., Lenard J.G. and Pietrzyk M., Materials Science and Engineering, 208 (1996) 249-259

[3] Majta J., Lenard J.G. and Pietrzyk M., ISIJ Int. 36 (1996) 1094-1102

$[4]$ M. Pietrzyk and J.G. Lenard, Thermal Mechanical Modeling of the Flat Rolling Process, SpringerVerlag. Berlin 1991

15/ Kochs L.F. "Superposition of Alloy Hardening, Strain Hardening, and Dynamic Recovery" Strength of Metals and Alloys, Hansen P.. Gerold V. and Kostorz G. Eds. Pergamon Press, Oxford, 3 (1979) pp. 423-430

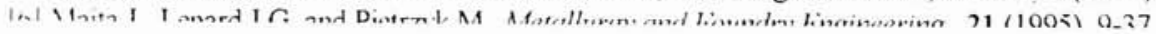

